\title{
AVALIAÇÃO DOS EFEITOS MICROCLIMÁTICOS DE DIFERENTES ZONAS CLIMÁTICAS LOCAIS EM CIDADE DE CLIMA TEMPERADO
}

\author{
EVALUATION OF MICROCLIMATIC EFFECTS OF LOCAL CLIMATE \\ ZONES IN A CITY WITH TEMPERATE CLIMATE
}

\author{
Eduardo Krüger 1 \\ Universidade Tecnológica Federal do Paraná, Curitiba, PR, Brasil, ekruger@utfpr.edu.br \\ Natasha Hansen Gapski Pereira ${ }^{2}$ \\ Universidade Federal de Santa Catarina, Florianópolis, SC, Brasil, natasha.gapski@gmail.com
}

\begin{abstract}
Resumo
O clima urbano é influenciado por características morfológicas e de uso e ocupação do solo. Aspectos como grau de verticalização, presença de vegetação e adensamento urbano influenciam diretamente sobre variáveis climáticas, gerando microclimas diferenciados na área urbana. Em relação ao conforto ambiental humano, a possibilidade de se prever fenômenos do clima urbano orienta decisões projetuais arquitetônicas e urbanísticas. Esta pesquisa teve por objetivo analisar diferenças térmicas intraurbanas a partir de dados meteorológicos coletados em estações amadoras participantes da rede Weather Underground, localizadas em diferentes zonas climáticas locais (Local Climate Zones - LCZs) em Londres, Inglaterra. Utilizaram-se dados meteorológicos de dez estações distribuídas nos eixos leste-oeste e norte-sul. Avaliou-se se as variações nos microclimas são significativas o bastante para suprir a demanda de energia para aquecimento e resfriamento de edificações, por meio do somatório de graus-hora de aquecimento e resfriamento para cada ponto. Pela análise do perfil longitudinal das temperaturas, a pesquisa constatou a formação de ilhas de calor nos locais com maior intensidade de uso e ocupação e menor cobrimento vegetal. Com relação à demanda por climatização artificial, notaram-se diferenças consideráveis em função da LCZ de cada ponto.
\end{abstract}

Palavras-chave: Clima urbano. Zonas climáticas locais. LCZ.

\begin{abstract}
Urban climate is influenced by morphological features and land use and occupation. Aspects such as vertical growth, presence of vegetation, and urban development directly affect various climates, generating differentiated microclimates in the urban area. Regarding outdoor thermal comfort, possibility to predict phenomena related to urban climate may guide design decisions in architecture and urban planning. This research aims to analyze intra-urban thermal differences from meteorological data collected from amateur weather stations belonging to the Weather Underground network, located in different Local Climate Zones (LCZs) in London, England. Meteorological data from ten amateur weather stations were used, which are distributed in east-west and north-south axes. The study evaluated if variations in microclimate are significant enough to define energy demand for cooling/heating using the sum of degree-hours for heating/cooling. The analysis of the longitudinal profile of intra-urban temperatures indicated that the generation of heat islands, with the highest intensity where land use and occupation are higher and with less vegetation cover. As for cooling/heating demand, obtained differences can be related to the LCZ each point belongs to.
\end{abstract}

Keywords: Urban climate. Local climate zones. LCZ.

How to cite this article:

KRÜGER, E.; PEREIRA, N. H. G. Avaliação dos efeitos microclimáticos de diferentes zonas climáticas locais em cidade de clima temperado. PARC Pesquisa em Arquitetura e Construção, v. 11, p. e020019, 28 set. 2020. DOI: https://doi.org/10.20396/parc.v11i0.8658794 


\section{Introdução}

Pesquisas sobre clima urbano revelam crescente preocupação com as mudanças climáticas, principalmente nas últimas décadas. O efeito das ilhas de calor, por exemplo, caracterizado pelo significativo aumento da temperatura em centros urbanos em comparação com zonas suburbanas ou com áreas rurais circundantes, é um fenômeno cada vez mais estudado e resultante da antropização dos espaços.

As primeiras observações sistemáticas do efeito de ilha de calor foram realizadas por Luke Howard e relatadas por ele em 1833, para Londres, Inglaterra, em seu livro The Climate of London (MILLS, 2008). À época, Howard se referia à área de Meteorologia como sendo ainda pouco explorada, e isso o motivou a coletar dados climáticos durante um período de 25 anos, entre 1806 e 1830, os quais foram publicados em periódicos diversos ao longo desse tempo. Tais dados se basearam em diferenças de temperatura observadas entre três pontos distantes da área urbana e a sede da Royal Society, situada no centro da cidade, comprovando haver uma relação entre os dados meteorológicos e as condições de urbanização (MILLS, 2008). Diversas características das ilhas de calor urbanas, comprovadas mais tarde por outros pesquisadores, como Oke (1982), Arnfield (2003), Stewart (2011), dentre outros, foram propostas por Howard, como seu efeito mais pronunciado ocorrendo durante a noite, o impacto do calor antropogênico e a variação de sua intensidade ocorrendo conforme as estações do ano e em função do grau de urbanização.

A partir do estudo pioneiro de Howard comprovando o efeito da ilha de calor londrina, inúmeros estudos foram realizados com foco no fenômeno da ilha de calor urbana, distribuídos ao longo de duas centenas de observações do fenômeno entre 1950-2007, sobretudo na América do Norte e no continente europeu (STEWART, 2011). Um dos assuntos de importância relacionados a essa área de investigação se deve à qualidade dos dados coletados e é de natureza metodológica, o que levou a algumas propostas de padronização (OKE, 2006). Em decorrência, protocolos foram sugeridos para essas pesquisas, como os de Aguilar et al. (2003) e de Oke (2004). Stewart (2011) mostra, a partir de sua revisão sistemática de estudos em clima urbano, que as maiores lacunas em grande parte dos trabalhos revisados são quanto à instrumentação e aos metadados, os quais não são corretamente reportados.

São diversos os fatores que afetam o clima urbano - a ocupação do solo, a presença de vegetação, a intensidade de tráfego, o nível de verticalização e os materiais construtivos empregados são variáveis que se distinguem entre diferentes regiões de uma cidade (UGEDA JÚNIOR; AMORIM, 2016). Em 2009, Stewart e Oke desenvolveram um método de classificação de regiões e climas urbanos denominado Local Climate Zones (LCZs ou Zonas Climáticas Locais) com o objetivo de refinar descritores além dos utilizados até então (estação urbana versus estação rural), sugerindo sua utilização para embasar estudos comparativos em torno da ilha de calor urbana. A classificação é realizada em função da morfologia da forma urbana, rugosidade, calor antropogênico e admitância térmica superficial. A aplicabilidade das LCZs na climatologia foi significativa desde sua implementação, sendo posteriormente criada uma base de dados mundial, o projeto World Urban Database and Access Portal Tools (http://www.wudapt.org/), com foco em estudos ambientais e tendo por objetivo adquirir e disseminar informação microclimática em cidades ao redor do mundo.

Considerando que a morfologia de uma região influencia o microclima local, assume-se que deveriam haver diferenças térmicas entre locais com diferentes atributos de morfologia urbana, uso e ocupação do solo, em outras palavras, contidos em diferentes LCZs. Assim, o presente trabalho se apoia no conceito de zonas climáticas locais de uma 
metrópole, analisando variações nos dados climáticos coletados em estações localizadas no meio urbano, a fim de verificar se variabilidades no microclima causam diferenças significativas na demanda por climatização artificial.

O objetivo deste artigo é analisar diferenças térmicas intraurbanas e suas implicações quanto à necessidade de condicionamento artificial (para resfriamento ou aquecimento) de edificações, a partir de dados coletados em estações amadoras participantes da rede Weather Underground (descrita mais adiante) localizadas em diferentes LCZs em Londres, Inglaterra. O estudo se concentra na malha urbana de Londres, sendo que a escolha pela capital inglesa se deu por duas razões fundamentais: a) disponibilidade de dados meteorológicos de superfície a partir de uma rede de estações amadoras; e b) disponibilidade de uma classificação prévia da área urbana segundo o critério das zonas climáticas locais.

O estudo, desta forma, tem sua relevância metodológica ao aliar uma classificação préexistente de LCZs em uma metrópole a uma rede de estações amadoras com espacialização e quantidade de pontos suficientes para uma abordagem por eixos urbanos definidos para análise. Neste caso, a opção por Londres baseou-se nesses dois aspectos. A título de comparação, das quatro cidades brasileiras que participam da rede WUDAPT, a maior delas, São Paulo capital, apresenta quantidade insuficiente de estações amadoras que disponibilizem dados em tempo real para uma análise como a realizada neste estudo, além do fato de a diversificação de LCZs em sua área central ser bem menor do que em Londres. As três outras cidades brasileiras com mapas de LCZs disponibilizados no WUDAPT (Aracaju-SE, Vitória-ES, Rio de Janeiro-RJ) apresentam quantidade ainda menor de estações amadoras em sua área urbana.

Na Fundamentação Teórica são descritas as Zonas Climáticas Locais e o monitoramento de variáveis meteorológicas em estações amadoras, dois elementos fundamentais tanto para a escolha da local de estudo como para o desenvolvimento do método adotado neste trabalho.

\section{Fundamentação Teórica}

\section{Zonas Climáticas Locais}

Zonas climáticas locais (LCZs) são definidas como regiões de distribuição de relativa uniformidade de temperatura superficial e do ar em escalas horizontais de $10^{2}$ a $10^{4}$ metros (STEWART; OKE, 2009), as quais influenciam a ilha de calor urbana. O sistema criado por Stewart e Oke (2012) consiste na classificação de locais com diferentes morfologias em 17 diferentes zonas climáticas locais. Cada LCZ é única por ser uma combinação da estrutura da superfície (edifícios/altura da árvore e espaçamento), cobertura (taxa de permeabilidade do solo), configuração (albedo, intercâmbio de calor) e metabolismo (fluxo de calor antropogênico). O primeiro relatório sobre as LCZs, publicado pela International Association for Urban Climate (STEWART, 2009) sugeriu sua utilização para embasar estudos comparativos em torno da Ilha de Calor Urbana.

As zonas climáticas locais identificadas pelos números de 1 a 10 representam os tipos de construções que compõem uma determinada região enquanto as identificadas pelas letras de $A$ a $G$ representam os vários tipos de cobertura vegetal ou processos associados a corpos d'água em uma região (STEWART; OKE, 2012).

Estudos da ilha de calor urbana, considerando a classificação morfológica em termos de zonas climáticas locais, de um modo geral, revelam uma relação entre tais zonas e o campo térmico resultante. Stewart, Oke e Krayenhoff (2014) mostraram que há relação discernível entre LCZs e a intensidade das ilhas de calor, sendo que locais com uma mesma classificação apresentaram condições térmicas semelhantes. Os autores 
alertam, porém, que condições de tráfego, relevo e cobrimento da superfície são parâmetros não uniformes nas LCZs que influem no microclima, daí a importância da escolha de locais que sejam verdadeiramente representativos de uma dada LCZ para medições, para não subestimar ou superestimar a magnitude da ilha de calor.

\section{Estações Meteorológicas Amadoras}

Uma alternativa para obtenção de dados meteorológicos em grande escala é a partir de bases de dados ou repositórios como o Weather Underground (www.wunderground.com), onde se disponibilizam dados coletados por estações amadoras. A quantidade de estações automáticas e a facilidade de se implementá-las com os avanços na área de desenvolvimento de sensores registradores permite acesso a dados em tempo real além de comparações entre diferentes estações que sejam parte de uma mesma rede (BELL; CORNFORD; BASTIN, 2013). No Reino Unido, a Weather Underground é a principal rede de estações amadoras, seguida da iniciativa WOW do Met Office. Bell, Cornford e Bastin (2013) sugerem como aplicações dessas redes nãooficiais seu uso para assimilação de dados de alta resolução, complementando dados de estações oficiais e também nos ajustes de modelos de predição. Quanto às variáveis medidas por essas estações, supõe-se que as medições de temperatura ofereçam relativa precisão, ocorrendo, porém, maior variabilidade nos dados de umidade relativa.

A rede Weather Underground é composta por mais de 2500 estações amadoras distribuídas globalmente (Figura 1). A concentração é maior na América do Norte e no continente europeu. $O$ uso de estações amadoras, não-oficiais, para complementação de dados de estações oficiais ou análise de áreas localizadas entre tais estações, pode ser enquadrado como uma contribuição colaborativa. A vantagem é possibilitar análises em regiões onde há poucas estações meteorológicas disponíveis, podendo-se então melhor lidar com a heterogeneidade urbana (CHAPMAN et al., 2015). Chapman, Bell e Bell (2017) comentam que o uso de redes existentes para crowdsourcing, como é o caso da Weather Underground, pode desempenhar importante papel na padronização das observações meteorológicas. Entretanto, estações amadoras podem conter uma série de falhas em sua instalação e também durante sua manutenção, sendo necessário verificar a consistência e a qualidade dos dados disponibilizados por elas (BELL; CORNFORD; BASTIN, 2013). No caso da rede Weather Underground, existe uma plataforma padronizada para disponibilização dos dados, sendo que informações relevantes acerca do equipamento e localização (metadados) são solicitadas pelo repositório quando do registro de uma nova estação.

Bell, Cornford e Bastin (2013) analisaram diferenças entre estações amadoras (Weather Underground e WOW) e oficiais (Met Office) na periferia de três cidades no Reino Unido, sendo duas delas no interior e uma próxima ao litoral. As estações estavam separadas em um raio de 5-10 km umas das outras. Diferenças em termos de temperatura foram mais visíveis e significativas durante o período diurno, o que pode evidenciar a influência de fatores como acesso solar e sombreamento local no microclima. Dados de umidade relativa apresentaram maior dispersão e as pressões atmosféricas tiveram diferenças dramáticas entre estações oficiais e amadoras. A resolução do equipamento de medição pode ter contribuído para parte das diferenças encontradas, estas, porém em muito se devem à instalação dos sensores e falta de uma manutenção periódica. 


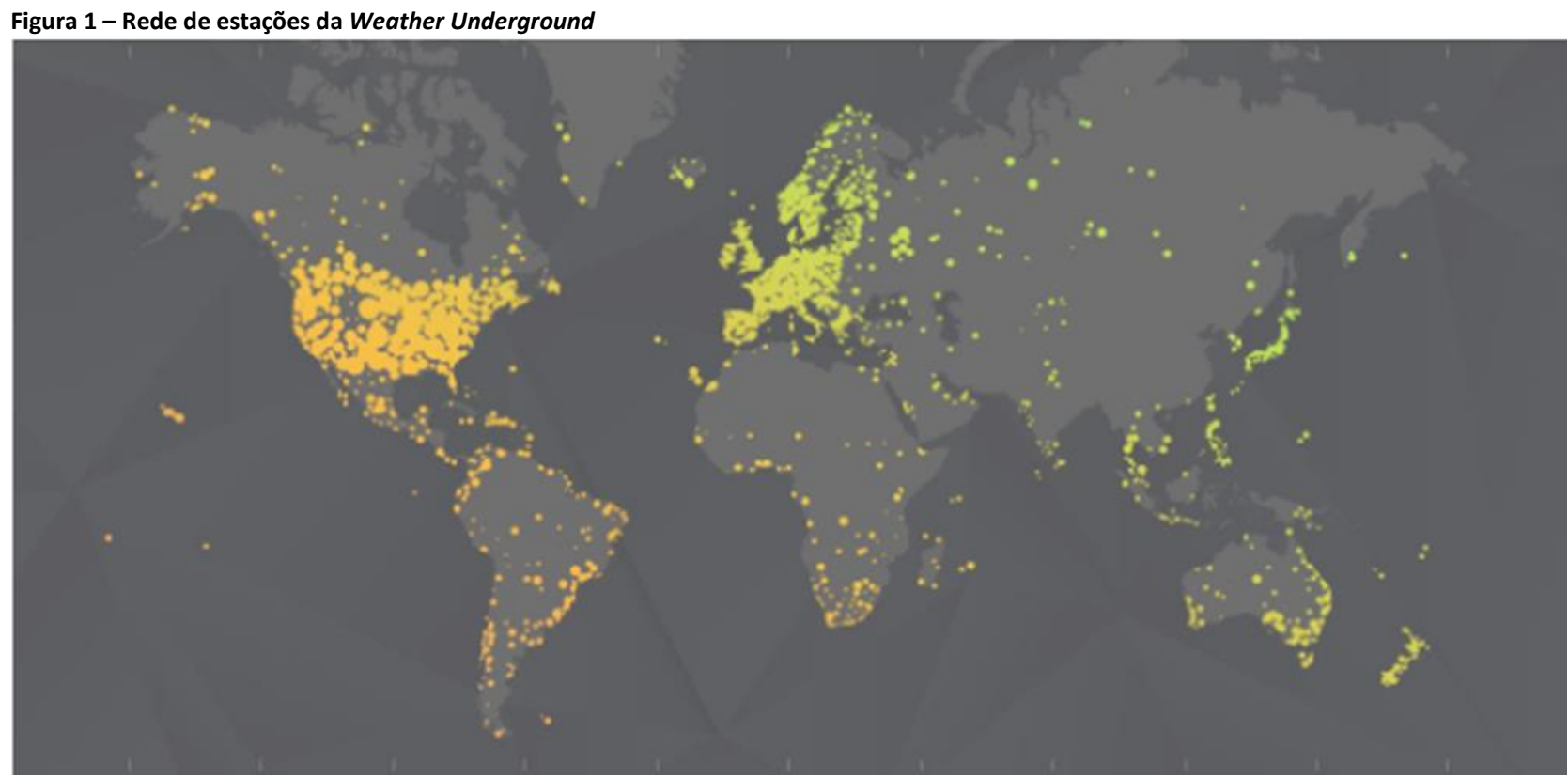

Fonte: www.wunderground.com.

\section{Método}

A metodologia aplicada neste trabalho se utiliza de uma classificação de LCZs para Londres, realizada por Geletic (2016). A partir da malha de pontos escolhidos da base de dados de estações amadoras da rede Weather Underground (2018), definiram-se dois eixos urbanos para análise. Deu-se então o processamento dos dados climáticos, com a comparação de diferenças térmicas intraurbanas e pela análise de demanda de climatização artificial pelo método do somatório de graus-hora/graus-dia.

\section{Definição de zonas climáticas locais e eixos de análise}

A cidade escolhida para realizar os estudos foi Londres, Reino Unido. Londres localizase na latitude $51^{\circ} 30^{\prime} 28^{\prime \prime} \mathrm{N}$ e longitude $0^{\circ} 7^{\prime} 41^{\prime \prime} \mathrm{W}$ e está a uma altitude média de 11 metros acima do nível do mar. Possui clima temperado oceânico $(\mathrm{Cfb})$ segundo a classificação de Köppen-Geiger (KOTTEK et al., 2006). O relevo londrino é predominantemente plano na região central de leste a oeste, há morros de baixa altitude ao norte e sul à medida em que se afasta da região central. Os ventos predominantes são oeste e sudoeste (CLOUT et al., 2019). A escolha dessa cidade foi pautada pela grande quantidade de estações meteorológicas oficiais e não-oficiais distribuídas em sua área urbana, algumas delas cadastradas na rede Weather Underground, e pela existência de uma classificação prévia das LCZs que compõem a área urbana.

A classificação das LCZs na área central, utilizada neste trabalho, foi desenvolvida por Geletic (2016) por meio de uma metodologia que utiliza sistema de informação geográfica conciliando análise de imagens de satélites com parâmetros de geometria e trocas de calor derivados das LCZs propostas por Stewart e Oke (GELETIC; LEHNERT, 2016). A metodologia descrita por Geletic e Lehnert (2016) foi desenvolvida e validada por esses autores para seis cidades da República Tcheca. Ressalta-se, porém, que a classificação realizada para Londres não passou pelo processo de filtragem e validação, no qual é realizado o ajuste da extensão da área de entorno (diâmetro das LCZs) de 100 para 300 metros, segundo preconizam Stewart, Oke e Krayenhoff (2014). Ao mesmo tempo, o raio de influência não é fixo e pode variar em diferentes localidades. Kolokotroni e Giridharan (2008) sugerem um raio de 50 metros (100 m de diâmetro) 
para Londres, neste caso a classificação de Geletic (2016) estaria adequada, apesar de incompleta segundo a metodologia que a originou.

Para análise, na definição dos eixos urbanos (Figura 2), os critérios adotados foram: 1) existência de estações meteorológicas de superfície em dois eixos com orientação axial aproximadamente leste-oeste e norte-sul, respectivamente; 2) verificação de completude e consistência dos dados climáticos da rede Weather Underground; 3) verificação de simultaneidade dos dados climáticos. Estações meteorológicas com menos de um ano de dados e com dados climáticos apresentando inconsistências notáveis foram desconsideradas. Consideraram-se inconsistentes as estações que apresentaram valores de temperatura constantes, demasiadamente altos ou baixos. Definiu-se então como ano de estudo o que se inicia em setembro de 2017 até agosto de 2018. Após a filtragem de estações com dados incompletos ou inconsistentes, traçaramse os dois eixos urbanos, plotados na Figura 3 sobre a classificação das LCZs apresentada por Geletic (2016).

Figura 2 - Eixos leste-oeste e norte-sul: pontos localizados no Google Earth de Londres, Inglaterra

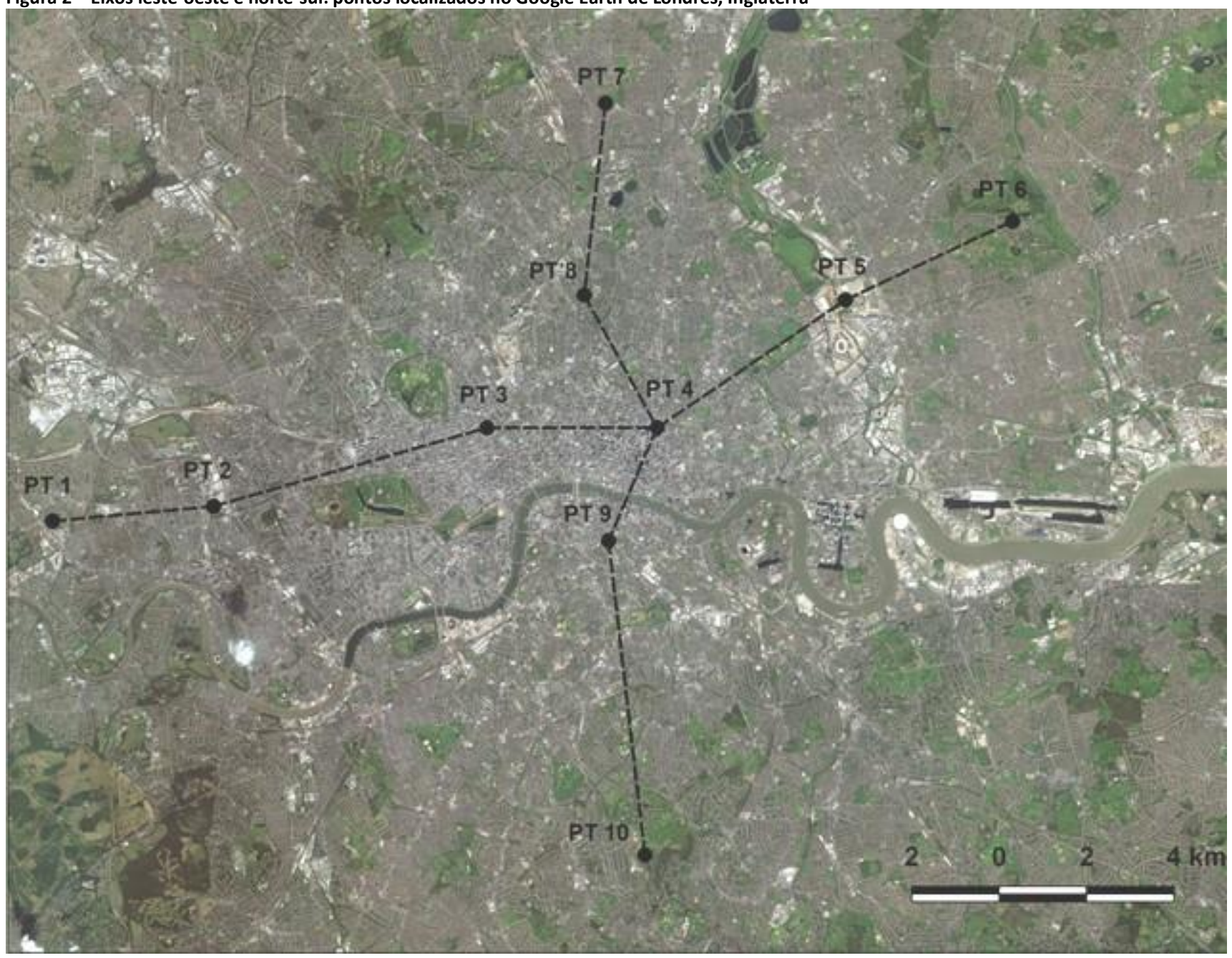

Fonte: adaptado de Geletic (2016) 


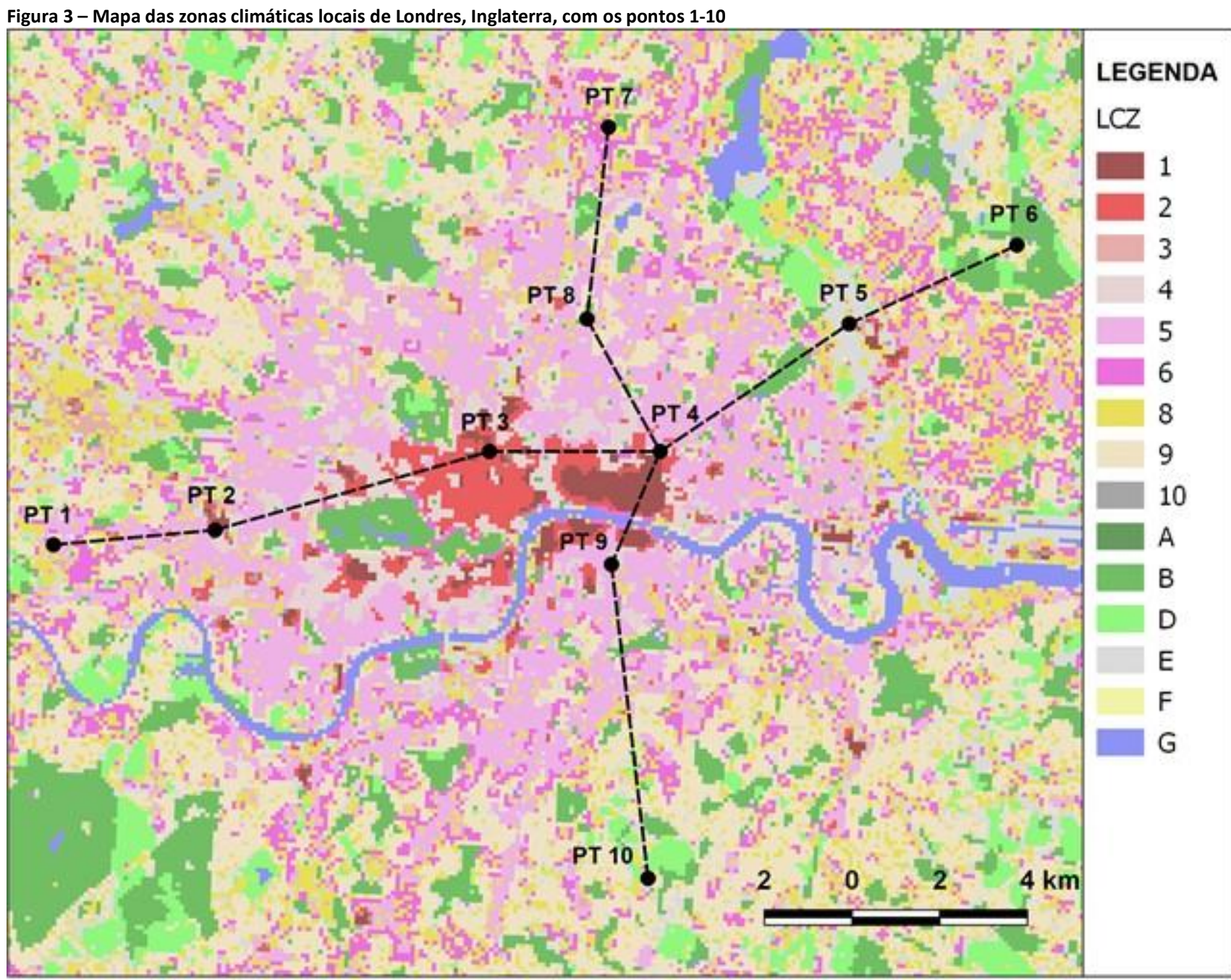

Fonte: adaptado de Geletic (2016).

Observa-se, na Figura 2, que na região central, onde estão localizados marcos históricos como o Big Ben e a Abadia de Westminster, predominam edificações mais adensadas e altas (como as do distrito financeiro de Londres), classificando-se estas como LCZs 1 e 2. Ao redor da zona central, nota-se uma melhor distribuição das edificações, sendo estas mais distanciadas e de alturas mais baixas, caracterizando-se como $L C Z$ 5. Por fim, nas regiões periféricas predomina a $L C Z$ 9, com construções de pequeno porte e maior permeabilidade aos ventos.

Em relação às zonas climáticas locais de cobertura natural, verifica-se principalmente a presença de áreas vegetadas em todo o mapa, representadas pelas $L C Z s \mathrm{~A}, \mathrm{~B}$ e $\mathrm{D}$, e a do rio Tâmisa que atravessa a cidade, LCZ G. Definidas as estações meteorológicas a serem utilizadas, classificaram-se as respectivas localidades segundo o mapa desenvolvido por Geletic (2016). Na Tabela 1 são listadas as estações meteorológicas analisadas, identificadas conforme sua nomenclatura no Weather Underground, suas coordenadas geográficas em graus decimais, elevação em metros e a $L C Z$ à qual cada uma pertence.

A estação ILONDON1407, ponto 4, é comum aos dois eixos urbanos e representa o ponto de interseção entre eles. Os metadados, disponíveis nas estações da Weather Underground, relativos às estações usadas na análise são também representados na Tabela 1. A rede do Weather Underground não fornece outras informações acerca da situação de instalação do equipamento, como altura em relação ao solo da estação propriamente dita e espacialização frente às edificações de entorno. 
KRÜGER, Eduardo; PEREIRA, Natasha Hansen Gapski

Avaliação dos efeitos microclimáticos de diferentes zonas climáticas locais em cidade de clima temperado

\begin{tabular}{|c|c|c|c|c|c|c|c|c|}
\hline Estação & $\begin{array}{c}\text { Pont } \\
0\end{array}$ & $L C Z$ & $\begin{array}{c}\text { Distância a partir } \\
\text { do ponto inicial } \\
(\mathrm{km})\end{array}$ & Lat $\left({ }^{\circ}\right)$ & Lon $\left({ }^{\circ}\right)$ & $\begin{array}{c}\text { Elevação } \\
\text { (m) }\end{array}$ & Hardware & Software \\
\hline \multicolumn{9}{|c|}{ EIXO LESTE-OESTE } \\
\hline ILONDON1172 & PT 1 & 6 & 0,0 & 51,503 & $-0,276$ & 28 & $\begin{array}{c}\text { Maplin N23DQ (WS- } \\
\text { 1001/HP1000) Weather Station }\end{array}$ & não informado \\
\hline ILONDON876 & PT 2 & 2 & 3,7 & 51,506 & $-0,223$ & 7 & Davis Vantage Pro2 (Wireless) & $\begin{array}{l}\text { Weatherlink.co } \\
\text { m } 1.10\end{array}$ \\
\hline ILONDON636 & PT 3 & 2 & 10,2 & 51,522 & $-0,133$ & 48 & não informado & $\begin{array}{c}\text { Weather logger } \\
\text { V2.2.0 }\end{array}$ \\
\hline ILONDON1407 & PT 4 & 4 & 14,1 & 51,522 & $-0,077$ & 21 & não informado & $\begin{array}{c}\text { WeatherRanger } \\
\text { V2.3.1 }\end{array}$ \\
\hline ILONDON579 & PT 5 & $\mathrm{E}$ & 19,3 & 51,548 & $-0,015$ & 14 & Davis Vantage Vue (Wireless) & Weeux-3.7.1 \\
\hline ILONDONL22 & PT 6 & 9 & 23,5 & 51,564 & 0,040 & 17 & Fine Offset & Cumulus v1.9.4 \\
\hline \multicolumn{9}{|c|}{ EIXO NORTE-SUL } \\
\hline ILONDON1334 & PT 7 & 6 & 0 & 51,588 & $-0,094$ & 22 & não informado & Pywws \\
\hline ILONDON1449 & PT 8 & 9 & 4,4 & 51,549 & $-0,101$ & 43 & Davis Vantage Pro2 (Cabled) & Wview-5.21.7 \\
\hline ILONDON1407 & PT 4 & 4 & 7,8 & 51,522 & $-0,077$ & 21 & não informado & $\begin{array}{c}\text { WeatherRanger } \\
\text { V2.3.1 }\end{array}$ \\
\hline ILONDON59 & PT 9 & 5 & 10,6 & 51,499 & $-0,093$ & 7 & Netatmo Weather Station & $\begin{array}{c}\text { Meteoware.co } \\
\mathrm{m}\end{array}$ \\
\hline ILONDON553 & $\begin{array}{l}\text { PT } \\
10\end{array}$ & 9 & 17,8 & 51,435 & $-0,081$ & 45 & não informado & $\begin{array}{c}\text { WeatherRanger } \\
\text { V2.3.1 }\end{array}$ \\
\hline
\end{tabular}

Fonte: elaborada pelos autores com base em Weather Underground (2018) e Geletic (2016).

\section{Processamento dos dados climáticos}

Devido à fonte de dados Weather Underground abranger uma rede de estações amadoras, frequentemente há falta de dados, seja por falha de conexão à internet, manutenção ou má configuração do equipamento. Desta forma, foi necessário adaptar o estudo aos dados disponíveis, sendo que, para as estações meteorológicas utilizadas neste estudo, não foi possível contar com dados contínuos das 8.760 horas do ano selecionado. Para possibilitar comparações a partir dos dados climáticos, compatibilizaram-se os registros para dados horários comuns a todas as estações nos 10 eixos urbanos, obtendo-se 10 conjuntos de 6.643 horas cada.

Assumindo que as diferenças obtidas entre pontos para o período noturno representam o calor armazenado pelas superfícies de entorno, o qual, em comparações com uma situação rural de referência, pode ser entendido como llha de Calor Urbana (ARNFIELD, 2003), foram gerados valores médios de temperatura do ar para cada ponto no período noturno. Para isso, foram determinados os horários de nascer e pôr do sol para cada data (TEETS, 2003), compatibilizando as séries para dados medidos coincidentes, sendo extraída a média de temperatura noturna. Adotou-se como critério um mínimo de $70 \%$ de horas por noite para obtenção da média noturna, excluindo noites com poucos dados. Considerando a variação sazonal de intensidade das ilhas de calor com maior magnitude no verão (ARNFIELD, 2003), calcularam-se as médias segundo as estações do ano. A distribuição dos dados por períodos e estações é apresentada na Tabela 2.

Com vistas a complementar a análise de diferenças térmicas intraurbanas, avaliou-se a necessidade de aquecimento ou resfriamento artificial para cada ponto, utilizando-se o procedimento do somatório de graus-hora, método simplificado de estimativa de demanda energética a partir das condições climáticas locais. Calculou-se o somatório das diferenças hora a hora relativamente a uma temperatura de referência (temperatura base ou de setpoint), obtendo-se uma medida de quanto e por quanto tempo se está abaixo ou acima dessa referência, para aquecimento ou resfriamento, 
respectivamente. Adotou-se como temperatura base para aquecimento o valor de $18{ }^{\circ} \mathrm{C}$ e para resfriamento $24^{\circ} \mathrm{C}$, de modo a se testar as variações resultantes.

\begin{tabular}{|c|c|c|c|}
\hline Estação do ano & Horas (total) & Horas (noite) & $\begin{array}{c}\text { Horas (noites c/ mínimo } \\
\text { de } 70 \% \text { de dados) }\end{array}$ \\
\hline Primavera & 2.017 & 827 & 593 \\
\hline Verão & 1.355 & 468 & 239 \\
\hline Outono & 1.840 & 964 & 671 \\
\hline Inverno & 1.431 & 866 & 536 \\
\hline Total & 6.643 & 3.125 & 2.039 \\
\hline
\end{tabular}

\section{Resultados}

Com o objetivo de identificar diferenças climáticas entre os pontos analisados e observar a influência da LCZ no microclima do entorno de cada ponto, foram feitas inicialmente análises da variação de temperatura e, em seguida, da demanda por climatização artificial por meio de somatórios de graus-dia e graus-hora de aquecimento e resfriamento.

\section{Variação de temperatura}

A Figura 4 (esquerda) apresenta o gráfico de temperatura noturna média para o eixo urbano leste-oeste por estação do ano. O gráfico evidencia o aumento da temperatura na região central da metrópole em todas as estações do ano, de forma consistente, particularmente nos pontos 3 e 4, caracterizando o fenômeno da ilha de calor. Segundo Yow e Carbone (2006), variações de temperatura maiores que $0,5^{\circ} \mathrm{C}$ são representativas de ilhas de calor. A diferença entre ambos os pontos 3 e 4 em termos de LCZ ( $L C Z 2$, compacto com altura mediana, versus $L C Z 4$, aberto e com altura elevada) parece não ter afetado as condições de temperatura durante a noite, com, no máximo, dois décimos de grau centígrado, nas estações de transição (primavera e outono). O ponto 6 , com as mais baixas temperaturas de todo o conjunto, se encontra em uma situação de LCZ 9 (terreno pouco construído). Tomando-se o ponto 4 como referência central, a diferença relativa de temperaturas considerando o ponto 6 foi superior a $1,3^{\circ} \mathrm{C}$ em todas as estações do ano.

Os perfis longitudinais do eixo urbano norte-sul são apresentados na Figura 4 (direita). Notam-se valores mais elevados de temperatura no ponto 9, o qual se localiza em $L C Z 5$, uma zona climática local (terreno aberto, com altura mediana das edificações) que, por suas características, não deveria gerar armazenamento térmico significativo no período noturno. O ponto com temperaturas mais baixas, ponto 10, novamente situa-se na LCZ 9 ("sparsely built" ou pouco construído). Assumindo-se que o ponto 9 tenha alguma anomalia (seja em suas medições ou em sua classificação), a diferença térmica do ponto 10 em relação ao ponto 4, mais central e de intersecção entre os dois eixos, foi significativamente maior do que a observada para o ponto 6 , com mesma $L C Z$ no eixo leste-oeste: atingiu-se uma diferença média de $2,2{ }^{\circ} \mathrm{C}$ nas noites de verão. 
Figura 4 - Perfis longitudinais da temperatura média noturna por estação do ano para o eixo urbano leste-oeste (à esquerda) e norte-sul (à direita) para Londres, Inglaterra
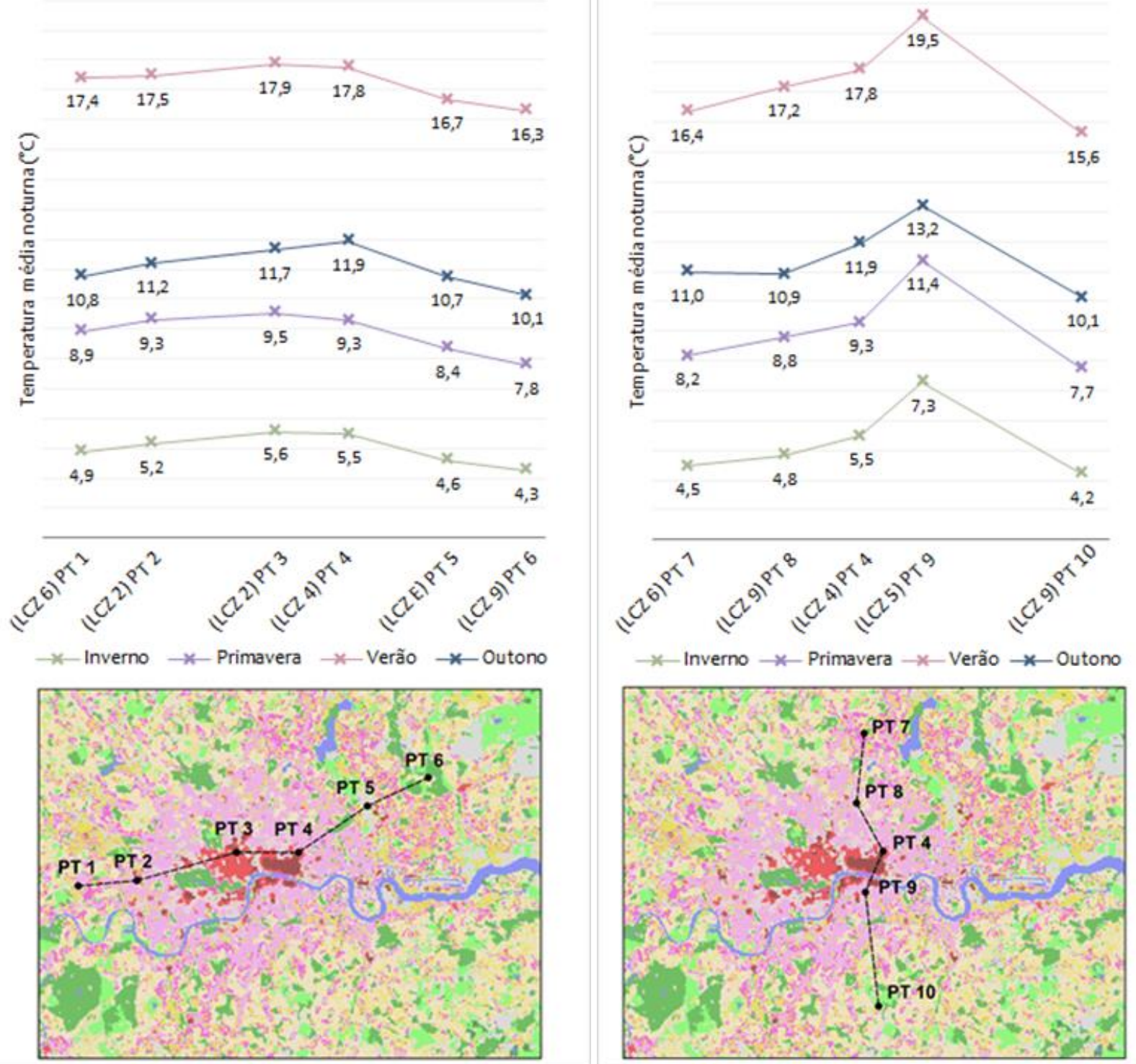

Fonte: os autores.

Ainda no eixo urbano norte-sul, os pontos 8 e 10, embora representativos de uma mesma LCZ (LCZ 9), apresentam uma diferença de até $1,7{ }^{\circ} \mathrm{C}$ no verão, com menor intensidade nas demais estações do ano. Tal diferença pode ser explicada pelo entorno da região, já que o ponto 8 se localiza em uma área mais urbanizada e o ponto 10 mais próximo a uma área verde. $O$ raio de influência do microclima relaciona-se com a geometria das edificações, rugosidade da superfície, velocidade e direção do vento. Para Stewart et al. (2014), as LCZs devem ter um raio mínimo a partir de 100 metros. No entanto, o raio mínimo utilizado por Geletic (2016) para a definição prévia das zonas climáticas é de 50 metros. Assim, é de se supor que os pontos tenham sofrido influência do entorno ( $L C Z$ 1), principalmente o ponto 10, rodeado de áreas verdes. Tal fato reforça também os achados de Skarbit et al. (2017) que, ao verificarem variações térmicas entre pontos localizados em uma mesma $L C Z$, denominadas pelos autores "Intra-class thermal diferences", as explicaram devido a características do entorno, impactando fluxos de ar entre $L C Z$ s por efeito de advecção local. 


\section{Somatório de graus-hora de aquecimento e resfriamento}

Para os dados coletados em cada ponto, as 6643 horas concomitantes da Tabela 2, obtêm-se os gráficos das Figuras 5 e 6 , com os somatórios de aquecimento e resfriamento, respectivamente, ordenados por $L C Z$ a partir dos pontos classificados como mais adensados até a $L C Z$ caracterizada por ser área aberta sem vegetação ( $L C Z$ E). Para a definição da ordem no caso de pontos com a mesma $L C Z$, observou-se o mapa da Figura 2, adequando-se às LCZ lindeiras.

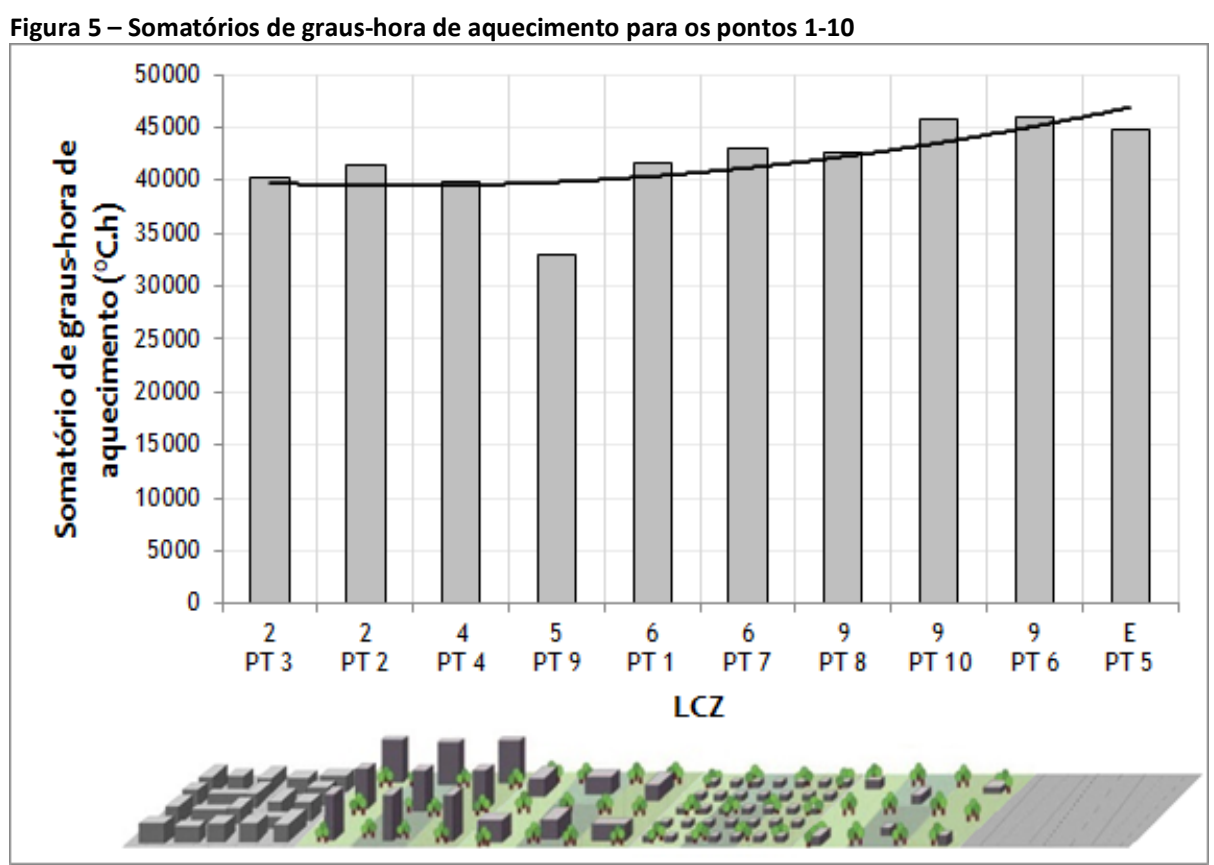

Nota: Coeficiente de determinação $\mathrm{R}^{2}=0,4815$. Fonte: os autores.

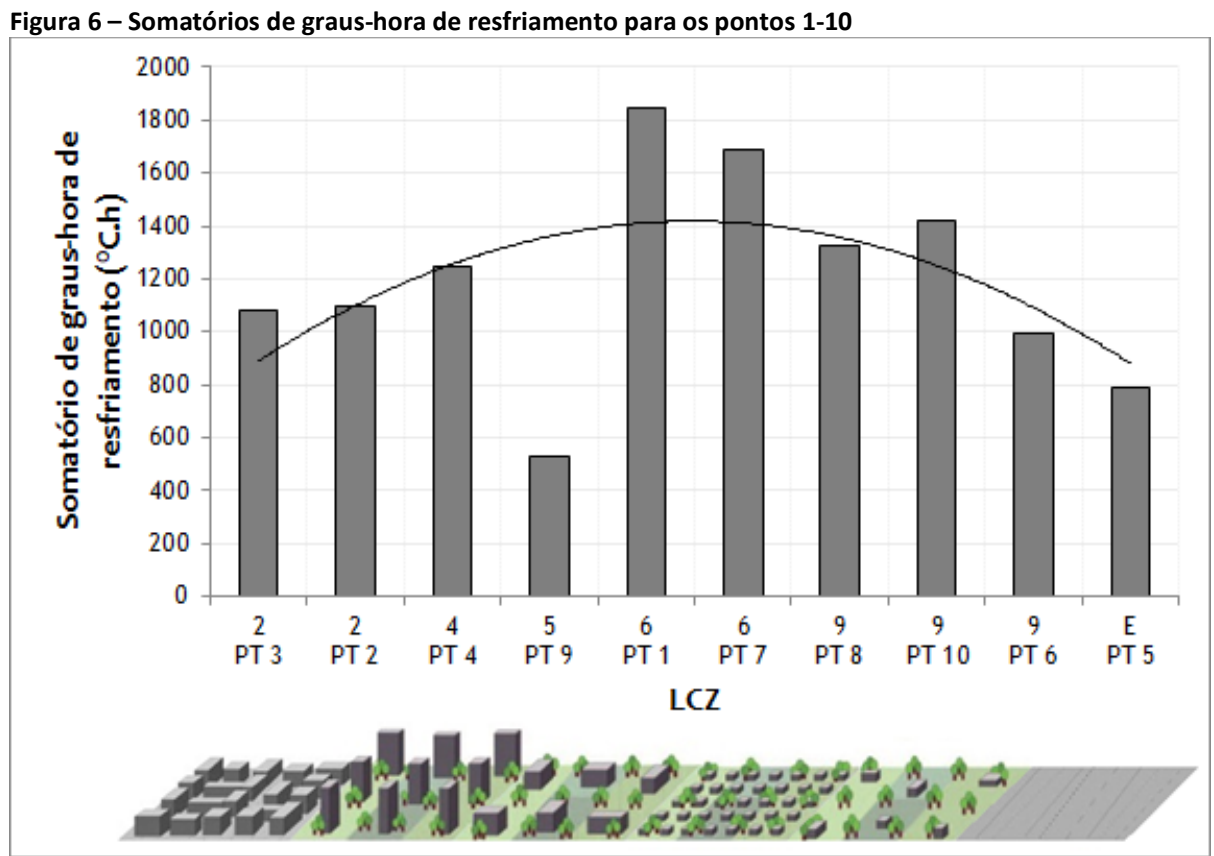

Nota: Coeficiente de determinação $\mathrm{R}^{2}=0,2599$. Fonte: os autores.

Como se trata do clima de Londres, cidade predominantemente fria, os somatórios para aquecimento são dominantes em seus totais, com valores superando os $30.000^{\circ} \mathrm{C}$.h, enquanto, para resfriamento, a variação se situa entre 500 e $2.000^{\circ} \mathrm{C}$.h. Observa-se, na Figura 6, que a demanda por aquecimento aumenta conforme se distancia das áreas 
mais adensadas da cidade, porém apresenta uma correlação baixa entre as variáveis demanda por climatização e $L C Z$ ordenada por grau de adensamento $\left(R^{2} \sim 0,5\right)$. No caso da demanda por resfriamento, não há uma tendência definida, sobressaindo os pontos com LCZ 6, porém com correlação ainda mais baixa, $R^{2} \sim 0,3$ (Figura 6 ). Assumindo que a demanda por resfriamento se dá principalmente durante o dia, a possível causa da baixa correlação deve-se principalmente aos ganhos solares e características de sombreamento no entorno de cada local, com ilhas de calor intercaladas com ilhas de frescor, as quais interferem na temperatura medida em cada estação e na relação com a LCZ de cada ponto (OKE, 2002). A LCZ 6, com construções baixas e espaçadas (open low rise), menos sujeita a sombreamentos de entorno e com pouca área vegetada, recebe potencialmente maior quantidade de radiação durante o dia, impactando positivamente na necessidade de resfriamento.

Note-se que, excluindo o ponto 9 das duas análises, devido ao seu comportamento anômalo na análise de diferenças de temperaturas, as correlações entre demanda em climatização e LCZ aumentam significativamente, com tendência crescente para a demanda para aquecimento e $\mathrm{R}^{2} \sim 0,8$. Quanto à demanda por resfriamento, ao se subtrair o ponto 9, a curva polinomial da Figura 6 se acentua, com $R^{2} \sim 0,8$, com os mesmos pontos 6 e 7 na dianteira.

\section{Somatório de graus-dia para aquecimento no período noturno}

Calculou-se também a demanda de aquecimento para o período noturno, ou seja, para o conjunto de 2.039 horas conforme a Tabela 2, porém assumindo como temperatura base $15,5{ }^{\circ} \mathrm{C}$, conforme padrão utilizado no Reino Unido (CARBON TRUST, 2010). Mantém-se uma relação semelhante à encontrada na Figura 4 (direita), porém com menor aderência a uma curva de tendência polinomial, resultando em um $\mathrm{R}^{2} \sim 0,4$ (Figura 7). Nota-se uma queda dos totais de demanda em relação aos totais gerais (cf. Figura 5), isso devido a três motivos: 1) pela filtragem dos dados noturnos para noites com pelo menos $70 \%$ das horas com registros; 2 ) por haver condições de frio também durante as horas do dia; e por se adotar desta vez uma temperatura base mais reduzida (de $18{ }^{\circ} \mathrm{C}$ para $15,5^{\circ} \mathrm{C}$ ). Os totais obtidos variam agora entre 600 e $1.400^{\circ} \mathrm{C}$.h.

Novamente, extraindo-se o ponto 9 como outlier, a linha de tendência linear atinge $\mathrm{R}^{2} \sim 0,7$, com relação inversa entre demanda por aquecimento e grau de adensamento.

Por fim, de modo a compatibilizar o tipo de estação meteorológica empregado em cada ponto, tomaram-se as três estações Davis (pontos 2, 5 e 8, com LCZs 2, "E" e 9, respectivamente, cf. Tabela 1), verificando-se a demanda por aquecimento para o mesmo período (Figura 8). 0 padrão de demanda para aquecimento obtido a partir do ordenamento das zonas climáticas locais é praticamente linear em função da natureza do entorno. Considerando que esses são pontos periféricos, não localizados na área central (cf. Figura 3), supõe-se que as características de uso e ocupação do solo tenham influído nas condições térmicas de cada um.

Quanto aos dados coletados pelas estações amadoras (neste artigo, considerou-se apenas a temperatura do ar), descuidos com a instalação e proteção adequada de sensores podem ter afetado a qualidade dos dados diurnos na análise realizada. No caso dos dados para o período noturno, verificou-se uma relação mais discernível entre zonas climáticas locais e condições térmicas, sendo tal relação ainda mais consistente no caso de estações meteorológicas de um mesmo fabricante (estações da Davis Instruments). Este fato comprova as vantagens citadas por Chapman, Bell e Bell (2017) do esquema de crowdsourcing para estudos de ilha de calor, pois o conjunto de estações utilizado, mesmo considerando-se que tenha havido discrepâncias entre pontos, ainda assim apresenta alterações visíveis nas condições térmicas locais em função das LCZs. Estas, 
por sua vez, têm seu uso reforçado quanto ao entendimento dos diversos microclimas urbanos.

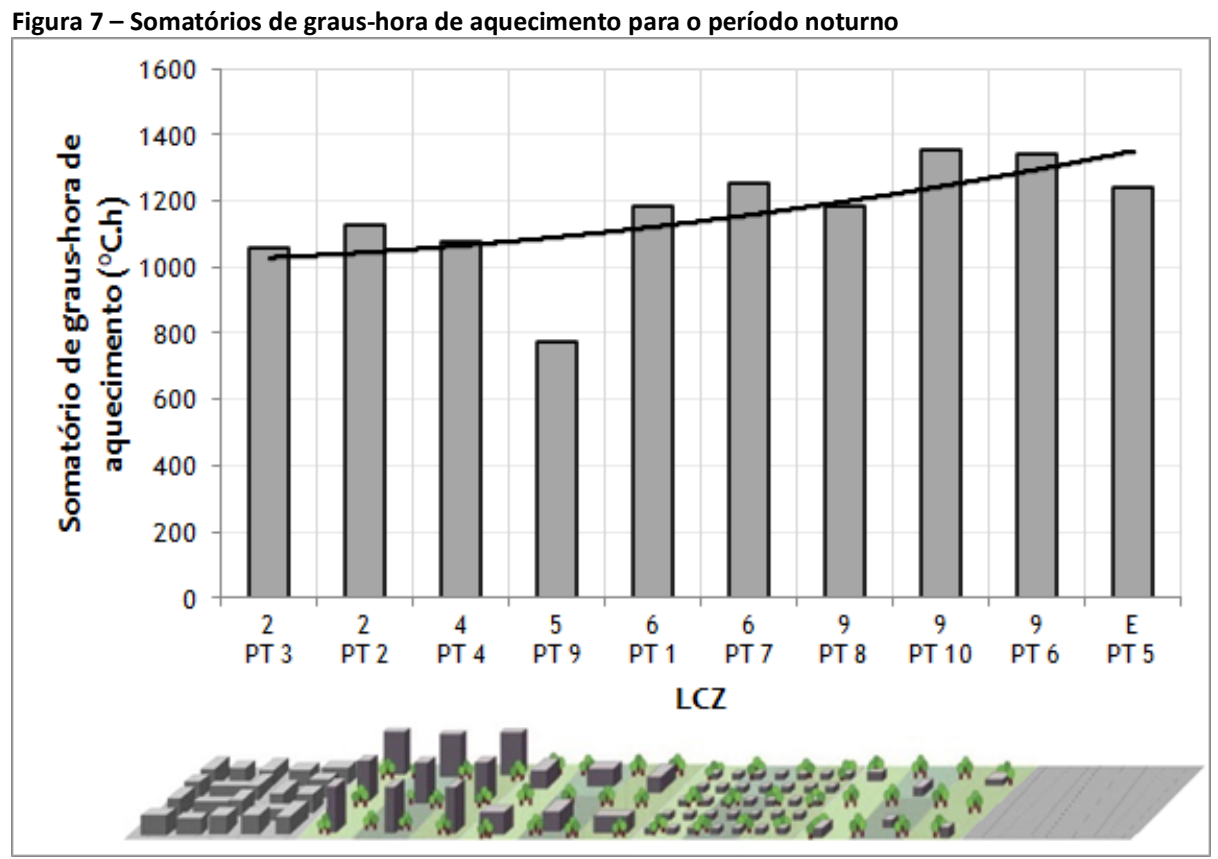

Nota: Coeficiente de determinação $\mathrm{R}^{2}=0,4255$. Fonte: os autores.

Figura 8 - Somatório de graus-hora para aquecimento para o período noturno, para as três estações da Davis Instruments

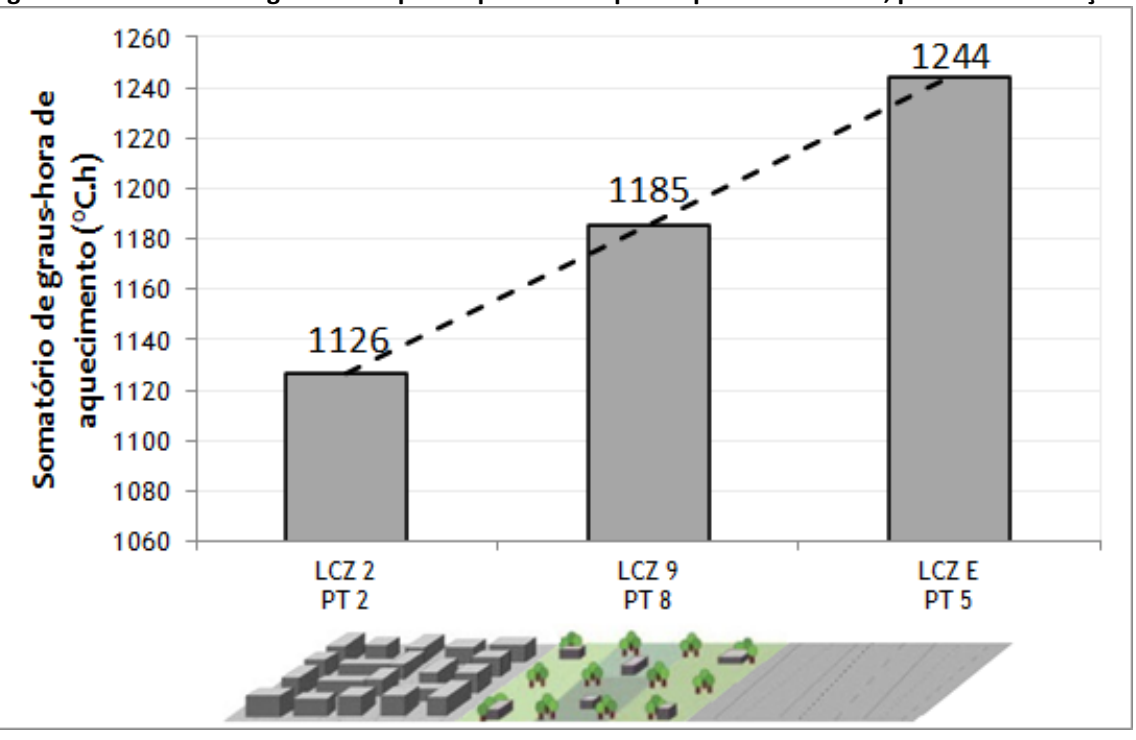

Fonte: os autores.

\section{Discussão}

Embora o objeto de estudo seja localizado na Inglaterra, o clima londrino se assemelha ao de algumas cidades brasileiras, como Curitiba, PR, também classificada como $\mathrm{Cfb}$ pela classificação de Köppen-Geiger (KOTTEK et al., 2006). A classificação do espaço urbano em zonas climáticas locais contribui para a previsibilidade da intensidade das ilhas de calor. O entendimento deste fenômeno possibilita melhor desenvolvimento de estratégias de mitigação dos efeitos negativos no planejamento urbano.

Reforçando o que dizem Chapman, Bell e Bell (2017), nota-se a vantagem de se considerarem estações não-oficiais para ampliar ainda mais as bases de estações meteorológicas oficiais que podem não apresentar boa distribuição espacial em áreas urbanas. Facilita-se, como no estudo realizado, a verificação da adequação de zonas 
climáticas locais face aos dados microclimáticos auferidos. Estações hospedadas em plataformas tais como a Weather Underground tendem a se aprimorar com o tempo, exigindo informações sobre tipo de estação, condições de instalação, etc. O uso desses dados pode, assim, contribuir para iniciativas tais como o WUDAPT, balizando melhor as definições de LCZs para áreas urbanas.

Como limitações, observam-se algumas inconsistências nos dados utilizados como base para a realização desse trabalho. Primeiramente, o mapa com a caracterização de zonas climáticas locais proposto por Geletic (2016) apresenta uma classificação ainda não ajustada, conforme a própria metodologia de Geletic e Lehnert (2016). Assim, uma dúvida que acompanha a interpretação de alguns pontos quanto à sua zona climática local é a transição de uma LCZ para outra, tornando a classificação obtida em muitos casos imprecisa. Com a elaboração da versão final do mapa de LCZs para Londres por Nial Buckley (2017) para a plataforma WUDAPT, atualmente em revisão, será possível refazer a análise, comparando resultados com o mapa de Geletic (2016). Uma comparação com o mapa atualmente disponível na plataforma, com a plotagem dos mesmos pontos (Figura 9), mostrou uma diferenciação de $L C Z$ entre pontos menor do que a do mapa utilizado neste artigo. No mapa de Buckley (2017), a variação compreende quatro classes de $L C Z$, contra seis classes no mapa de Geletic (2016).

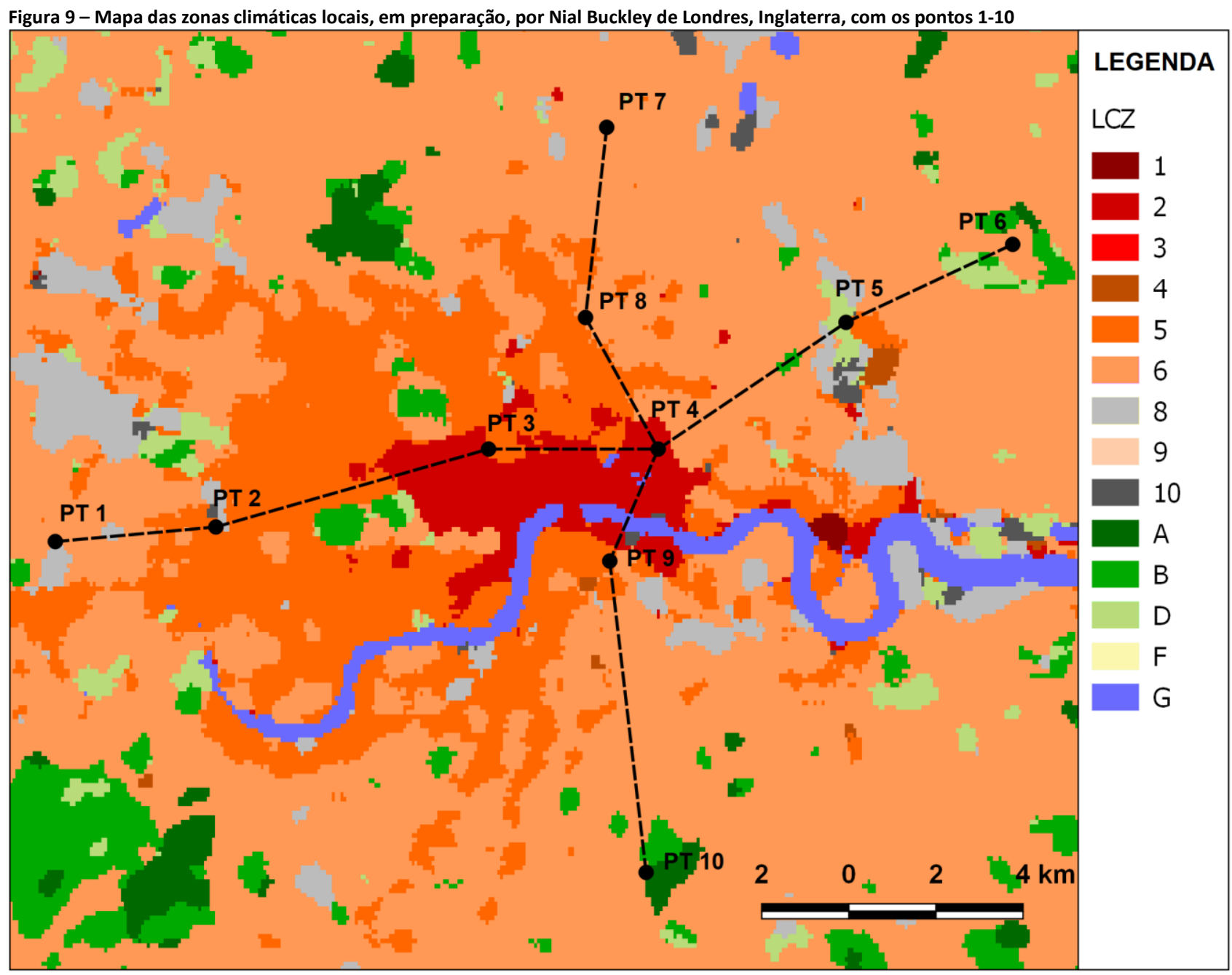

Fonte: adaptado de Buckley (2017).

Um aprimoramento do método poderia também incluir monitoramentos in loco, ao invés de se trabalhar com dados de estações amadoras. Esse tipo de monitoramento, 
entretanto, depende de iniciativas de pesquisa com instalação de estações medidoras para mapeamento térmico ou análise correlacional entre condições térmicas e LCZs. Tanto no Brasil como internacionalmente há trabalhos publicados nesse sentido (LELOVICS et al., 2014; ŠEĆEROV et al., 2015; SKARBIT et al., 2017; MASIERO; SOUZA, 2018; CARDOSO; AMORIM, 2018).

No entanto, o método proposto neste estudo utiliza-se de dados acessíveis remotamente. Uma alternativa seria então utilizar imagens de satélite, conforme análises realizadas para São Paulo por Ferreira e Duarte (2019) usando imagens Aqua/MODIS LST, o mapa WUDAPT para a Região Metropolitana, por Cai et al. (2018), ou para o Delta do Rio Yangtze por Xu et al. (2017) para cidades com grande densidade populacional na China. Nesse caso, há necessidade de conhecimento de ferramentas de GIS para interpretação e manejo das imagens satelitais. Além disso, as temperaturas estimadas são do momento da passagem do satélite pela localidade (portanto, estáticas), enquanto que as obtidas por estações meteorológicas são dinâmicas, sendo mais adequadas para análise de demanda energética.

A verificação da adequação do princípio das zonas climáticas locais e do que estas representam em termos de propriedades físicas (obstrução do céu, fração de área construída, rugosidade, calor antropogênico) foi observada em estudo anterior (EMMANUEL; KRÜGER, 2012), no qual dados meteorológicos de quatro estações da rede Weather Underground foram avaliados em função de sua LCZ. Nesse estudo, estações periféricas à região central de Glasgow, Escócia, com diferentes zonas climáticas locais, apresentaram diferentes padrões microclimáticos, sendo estes mais perceptíveis no período noturno, segundo uma relação inversa de demanda de aquecimento versus condição de adensamento. No estudo de Emmanuel e Krüger (2012), as diferenças térmicas entre as quatro estações amadoras analisadas se mantiveram tanto anualmente como nas estações de verão e inverno, sendo, contudo, mais marcantes no inverno.

Por fim, deve-se assumir que haja imprecisões nos dados meteorológicos obtidos nas estações amadoras analisadas neste artigo, portanto, a qualidade dos dados deve ser verificada. No estudo realizado, prezou-se em manter uma compatibilidade temporal dos dados, subtraindo linhas que não estivessem completas por todas as estações. Verificações quanto aos valores máximos e mínimos medidos também podem ser facilmente realizadas. Verificações complementares podem ir das mais simples, se servindo do processo denominado "buddy checking", ao compararam-se dados de estações amadoras com os de estações oficiais próximas, a processos mais complexos, como procedimentos de comparação usando sistemas geoespaciais (GALARUS; ANGRYK; SHEPPARD, 2012).

\section{Conclusões}

O trabalho realizado mostrou a aplicabilidade dos dados de uma rede de estações meteorológicas amadoras ao estudo de diferenças térmicas e estimativas de demanda por aquecimento e resfriamento em função da classificação de cada ponto quanto às zonas climáticas locais. Apesar da baixa correlação encontrada entre as LCZs e a demanda de aquecimento e resfriamento, os perfis longitudinais de temperatura média noturna demonstraram a presença de ilhas de calor com maior intensidade em áreas mais adensadas. De maneira geral, os locais mais próximos à área central se mostraram mais confortáveis termicamente, enquanto os mais afastados desta, ou próximos a áreas verdes são mais desconfortáveis e de maior demanda por aquecimento artificial.

Concluindo, a cidade de Londres, por si, embora seja representativa de estudos passados sobre clima urbano conforme apontado na Introdução, não foi 
necessariamente o que definiu o objeto de estudo deste trabalho. Dois aspectos foram fundamentais na escolha dessa cidade: a existência de uma classificação preliminar das LCZs em sua área urbana e a disponibilidade de um conjunto de estações meteorológicas amadoras, participante da rede Weather Underground. Conforme mencionado, a classificação $\mathrm{Cfb}$ de Londres tem alguma representação, mesmo que pequena, no território brasileiro.

\section{Referências}

AGUILAR, E.; AUER, I.; BRUNET, M.; PETERSON, T. C.; WIERINGA, J. Guidance on metadata and homogenization. WMO/TD No. 1186. Geneva: Weather Meteorological Organization, 2003. 53 p.

ARNFIELD, A. J. Two decades of urban climate research: a review of turbulence, exchanges of energy and water, and the urban heat island. International Journal of Climatology, v. 23, p.1-26, 2003.

DOI:https://doi.org/10.1002/joc.859

BELL, S.; CORNFORD, D.; BASTIN, L. The state of automated amateur weather observations. Weather, v. 68, n. 2, p. 36-41, 2013. DOI:https://doi.org/10.1002/wea.1980

BUCKLEY, N. WUDAPT level o London: Datasheet for WUDAPT Level o Product, v. 0.33. World Urban Database and Access Portal Tools. 12 jun. 2017. [Training data London_NialBuckly_TK_MF_20170612]. Disponível em:

https://wudapt.cs.purdue.edu/wudaptTools/static/Layers/London/html/_factsheet.html. Acesso em: 3 jul. 2020

CAI, M. et al. Investigating the relationship between local climate zone and land surface temperature using an improved WUDAPT methodology-A case study of Yangtze River Delta, China. Urban Climate, v. 24, p. 485-502, 2018. DOI:https://doi.org/10.1016/j.uclim.2017.05.010

CARBON TRUST. Degree days for energy management: A practical introduction. London: Carbon Trust, 2010. Disponível em: http://lowcarbonswansea.weebly.com/uploads/5/8/4/7/5847606/ctgo04.pdf. Acesso em: 16 dez. 2019.

CARDOSO, R.S.; AMORIM, M.C.C.T. Urban heat island analysis using the 'local climate zone' scheme in Presidente Prudente, Brazil. Investigaciones Geográficas, v. 69, 2018. DOI: http://dx.doi.org/10.14198/INGEO2018.69.07

CHAPMAN, L. et al. The Birmingham urban climate laboratory: An open meteorological test bed and challenges of the Smart City. Bulletin of the American Meteorological Society, v. 96, n. 9, p.1545-1560, 2015.

DOI:https://doi.org/10.1175/BAMS-D-13-00193.1

CHAPMAN, L.; BELL, C.; BELL, S. Can the crowdsourcing data paradigm take atmospheric science to a new level? A case study of the urban heat island of London quantified using Netatmo weather stations. International Journal of Climatology, v. 37, n. 9, p.3597-3605, 2017. DOI:https://doi.org/10.1002/joc.4940

CLOUT, H.D. et al. London. In: ENCYCLOPÆDIA Britannica. Chicago: Britannica. 2019. Disponível em: https://www.britannica.com/place/London. Acesso em: 28 jun. 2020.

EMMANUEL, R.; KRÜGER, E. Urban heat island and its impact on climate change resilience in a shrinking city: The case of Glasgow, UK, Building and Environment, v. 53, p.137-149, jul. 2012.

DOI:https://doi.org/10.1016/j.buildenv.2012.01.020

FERREIRA, L. S.; DUARTE, D. H. S. Exploring the relationship between urban form, land surface temperature and vegetation indices in a subtropical megacity. Urban Climate, v. 27, p. 105-123, 2019.

DOl:https://doi.org/10.1016/j.uclim.2018.11.002

GALARUS, D. E.; ANGRYK, R.; SHEPPARD, J. Automated Weather Sensor Quality Control. In: INTERNATIONAL FLAIRS CONFERENCE FLAIRS, 25., 2012, Florida. Proceedings [... ]. Florida: FLAIRS, 2012. p. 388-393. 
GELETIC, J.. Local climate zones in London, ResearchGate, 2016. [ZIP archive contains LCZ layer created using Stewart and Oke (2012) classification]. Disponível em: https://doi.org/10.13140/RG.2.2.25121.20328. Acesso em 10 jun. 2018.

GELETIC, J.; LEHNERT, M. GIS-based delineation of local climate zones: The case of medium-sized Central European cities. Moravian Geographical Reports, v. 24, n. 3, p. 2-12, set. 2016. DOI:https://doi.org/10.1515/mgr-2016-0012

KOLOKOTRONI, M.; GIRIDHARAN, R. Urban heat island intensity in London: An investigation of the impact of physical characteristics on changes in outdoor air temperature during summer. Solar Energy, v. 82, n. 11, p. 986998, nov. 2008. DOI:https://doi.org/10.1016/j.solener.2008.05.004

KOTTEK, M. et al. World Map of the Köppen-Geiger climate classification updated. Meteorologische Zeitschrift, v. 15, n. 3, p. 259-263, 10 jul. 2006. DOI:https://dx.doi.org/10.1127/0941-2948/2006/0130

LELOVICS, E. et al. Design of an urban monitoring network based on Local Climate Zone mapping and temperature pattern modelling. Climate research, v. 60, n. 1, p. 51-62, 2014. DOI:https://doi.org/10.3354/cr01220

MASIERO, E.; SOUZA, L. C. L. Mapping humidity plume over local climate zones in a high-altitude tropical climate city, Brazil. Ambiente Construído, v. 18, n. 4, p. 177-197, 2018. DOI:https://doi.org/10.1590/s1678-86212018000400300

MILLS, G. Luke Howard and the climate of London. Weather, v. 63, n. 6, p. 153-157, jun. 2008.

DOI:https://doi.org/10.1002/wea.195

OKE, T. R. The energetic basis of the urban heat island. Quarterly Journal of the Royal Meteorological Society, v. 108, n. 455, p. 1-24, jan. 1982. DOI: https://doi.org/10.1002/qj.49710845502

OKE, T. R. Boundary layer climates. $2^{\text {nd }}$ ed., Abingdon: Routledge, 2002. 435 p.

OKE, T. R. Initial guidance to obtain representative meteorological observations at urban sites. World Meteorological Organization, 2004. (WMO/TD- No. 1250; IOM Report n. 81).

OKE, T. R. Towards better scientific communication in urban climate. Theoretical and Applied Climatology, v. 84, n. 1-3, p. 179-190, fev. 2006. DOI:https://doi.org/10.1007/s00704-005-0153-0

ŠEĆEROV, I. et al. Development of an automated urban climate monitoring system in Novi Sad (Serbia). Geographica Pannonica, v. 19, n. 4, p. 174-183, 2015. DOI:https://doi.org/10.5937/GeoPan1504174S

SKARBIT, N. et al. Employing an urban meteorological network to monitor air temperature conditions in the 'local climate zones' of Szeged, Hungary. International Journal of Climatology, v. 37, p. 582-596, ago. 2017. DOI:https://doi.org/10.1002/joc.5023

STEWART, I. D. Classifying urban climate field sites by “Local Climate Zones". Urban climate news, v. 34, n. 4, p. 8-11, dec. 2009. Disponível em: http://www.urban-climate.org/newsletters/IAUC034.pdf. Acesso em 23 jun. 2020.

STEWART, I. D. A systematic review and scientific critique of methodology in modern urban heat island literature. International Journal of Climatology, v. 31, n. 2, p. 200-217, 2011. DOI:https://doi.org/10.1002/joc.2141

STEWART, I. D.; OKE, T. R. Newly developed "thermal climate zones" for defining and measuring urban heat island magnitude in the canopy layer. In: SYMPOSIUM ON URBAN ENVIRONMENT, 8., 2009, Phoenix. Proceedings [... ]. Phoenix: AMS, 2009.

STEWART, I. D.; OKE; T. R. Local Climate Zones for Urban Temperature Studies. Bulletin of the American Meteorological Society. v. 93, n. 12, p. 1879-1900, mai. 2012. DOI: https://doi.org/10.1175/BAMS-D-11-00019.1

STEWART, I. D.; OKE, T. R.; KRAYENHOFF, E. S. Evaluation of the 'local climate zone' scheme using temperature observations and model simulations. International Journal of Climatology, v. 34, n. 4, p. 1062-1080, 2014. DOI:https://doi.org/10.1002/joc.3746 
TEETS, Donald A. Predicting sunrise and sunset times. The College Mathematics Journal, v. 34, n. 4, p. 317-321, 2003.

UGEDA JÚNIOR, J. C.; AMORIM, M. C. C. T. Reflexões acerca do sistema clima urbano e sua aplicabilidade: pressupostos teórico-metodológicos e inovações técnicas. Revista do Departamento de Geografia, Universidade de São Paulo, n. spe, p. 160-174, 24 out. 2016. DOI:https://doi.org/10.11606/rdg.voispe.119402

$\mathrm{XU}$, Y. et al. Classification of local climate zones using ASTER and Landsat data for high-density cities. IEEE Journal of Selected Topics in Applied Earth Observations and Remote Sensing, v. 10, n. 7, p. 3397-3405, 2017. DOI:https://doi.org/10.1109/JSTARS.2017.2683484

YOW, D. M.; CARBONE, G. J. The urban heat island and local temperature variations in Orlando, Florida. Southeastern Geographer, Athens, v. 46, n. 2, p. 297-321, out. 2006. DOI:https://doi.org/10.1353/sgo.2006.0033

\section{${ }^{1}$ Eduardo Krüger}

Engenheiro Civil. Doutor em Arquitetura (Leibniz Universität Hannover, Alemanha). Professor Titular da Universidade Tecnológica Federal do Paraná (UTFPR), professor do Departamento de Construção Civil e do Programa de Pós-Graduação em Engenharia Civil. Endereço postal: UTFPR / Campus Curitiba / Sede Ecoville, Rua Deputado Heitor Alencar Furtado, 4900, Curitiba, PR, CEP 81280-340.

\section{${ }^{2}$ Natasha Hansen Gapski Pereira}

Engenheira Civil. Mestranda em Engenharia Civil no Programa de Pós-Graduação em Engenharia Civil da Universidade Federal de Santa Catarina. Endereço postal: Caixa Postal 476. Campus UFSC - Trindade, PPGEC/CTC, Florianópolis, SC, Brasil, CEP 88040-970. 